\title{
Frequency Reconfiguration Mechanism of a PIN Diode on a Reconfigurable Antenna for LTE and WLAN Applications
}

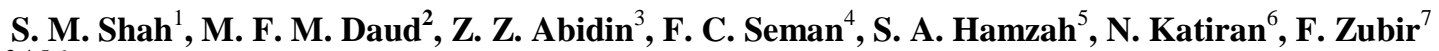 \\ 1,2,3,4,5,6 Research Centre for Applied Electromagnetics, Universiti Tun Hussein Onn Malaysia, 86400 Batu Pahat, Johor, \\ Malaysia \\ ${ }^{7}$ Faculty of Electrical Engineering, Universiti Teknologi Malaysia, 81310 Skudai, Johor, Malaysia
}

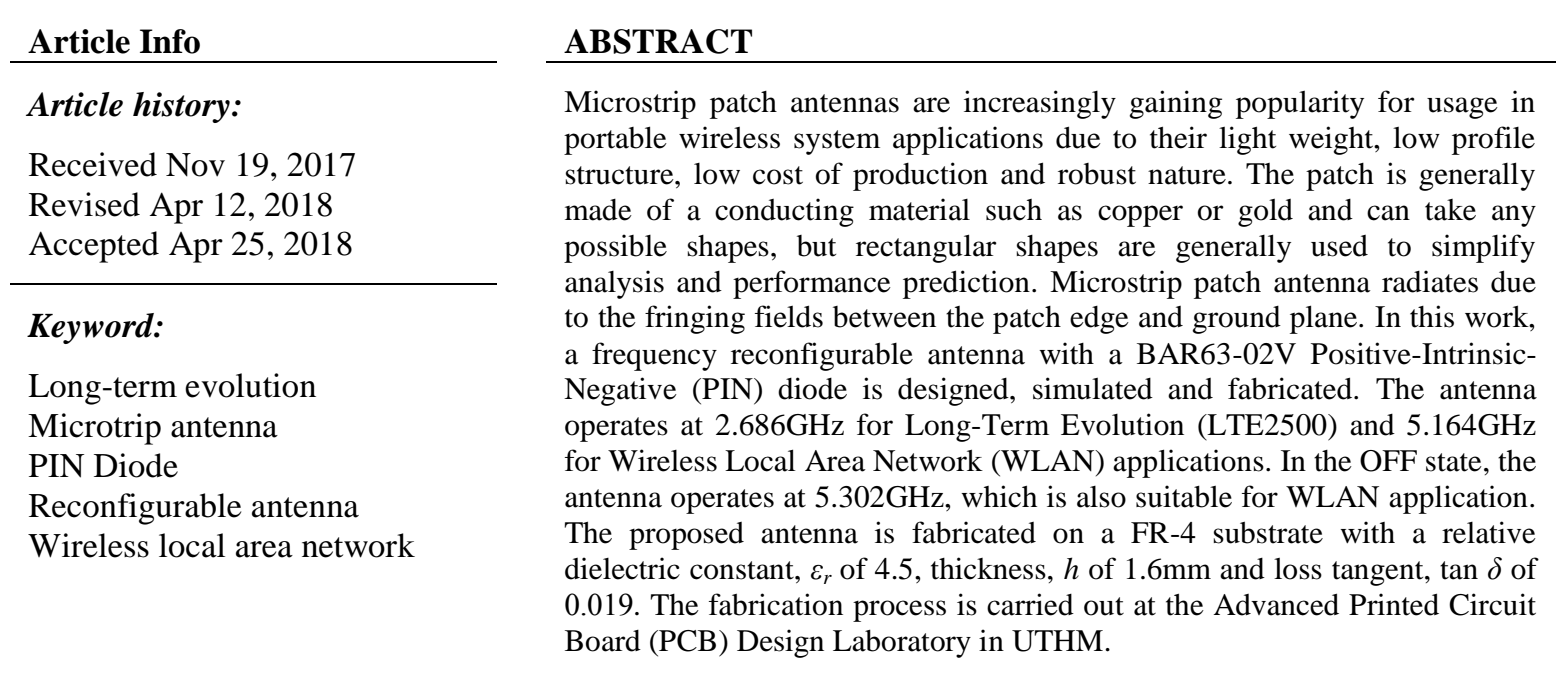

Copyright $(0) 2018$ Institute of Advanced Engineering and Science. All rights reserved.

\section{Corresponding Author:}

Shaharil Mohd Shah,

Research Centre for Applied Electromagnetics,

Universiti Tun Hussein Onn Malaysia,

86400 Batu Pahat, Johor, Malaysia.

E-mail: shaharil@uthm.edu.my

\section{INTRODUCTION}

There are numerous wireless communication systems in our daily lives such as cellular radio systems, mobile satellite systems and wireless local area networks. Although it is hard to predict precisely how the systems will appear in the future, it is clear that there will be a need for new solutions in the field of antennas. The new solutions are commonly to cater for the need to include the growing number of communication services in a single mobile device such as Wireless Local Area Network (WLAN), Worldwide Interoperability for Microwave Access (WiMAX), Long Term Evolution (LTE) and satellite communication, only to name a few [1]. In this context, there is an evident interest in developing new reconfigurable antennas, which allow dynamic reconfiguration of parameters such as operating frequency, radiation pattern and polarization [2].

Reconfigurable antennas have the ability to simultaneously operate in different frequency bands for different communication services [3]. Therefore, to operate in multiple frequency bands with improved radiation efficiency, the RF engineers are focusing on designing reconfigurable antenna. There are many ways of reconfiguring the antennas such as by using active switches and tunable devices. The development of active components such as PIN diodes, varactor diodes and RF MEMS, has accelerated the rapid evolution of the reconfigurable antennas [4]. Recently, PIN diodes have been used as the switching elements in the 
reconfigurable antennas for the purpose of multiple frequency bands operation [5]. In addition, reconfigurable antenna can be a cheaper alternative to traditional adaptive arrays [6].

Microstrip patch antennas are increasingly gaining popularity for use in portable wireless system applications due to their light weight, low profile structure, low cost of production and robust nature [7]. In its most basic form, a microstrip patch antenna consists of a radiating patch on one side of a dielectric substrate and a ground plane on the other side. The patch is generally made of a conducting material such as copper or gold and can take any possible shape, but regular shapes are generally used to simplify analysis and performance prediction [8]. The radiating patch and the feed lines are usually photo-etched on the dielectric substrate. Microstrip patch radiate due to the fringing fields between the patch edge and ground plane.

In this work, a frequency reconfigurable antenna with a PIN diode will be designed, simulated and fabricated. PIN diodes have been used for RF switching of reconfigurable antennas in many applications such as mobile and satellite communications, cellular radio system and radar application. PIN diodes is a current controlled device that operates as a variable resistor in the RF switching operation. PIN diodes have many advantages such as small in size, high switching speed, low distortion, low insertion loss, good isolation with low power handling and low in cost [9]. The operation of PIN diode is based on the ON or OFF states of the PIN diodes. The antenna will operate at WLAN frequency $(5.15 \mathrm{GHz}-5.825 \mathrm{GHz})$ and LTE2500 frequency $(2.5 \mathrm{GHz}-2.69 \mathrm{GHz})$. The Computer Simulation Technology Microwave Studio (CST MWS) software is used to design and simulate the reconfigurable antenna. The proposed antenna is fabricated on a FR-4 substrate with a relative dielectric constant, $\varepsilon_{r}$ of 4.5 , thickness, $h$ of $1.6 \mathrm{~mm}$ and loss tangent, $\tan \delta$ of 0.019 . The fabrication process is carried out at the Advanced Printed Circuit Board (PCB) Design Laboratory.

\section{RESEARCH METHODOLOGY}

\subsection{Antenna design and configuration}

The design and simulation processes are done by using CST MWS ${ }^{\circ}$ software. The simulation result is optimized to achieve the best performance of antenna. Then, In order to achieve the required reconfiguration, the antenna is designed in an orderly manner which involved two stages. Firstly, the proposed antenna comprises of only the main radiating plane which is fed by a microstrip line with a stub for impedance matching. Secondly, an additional radiating plane is added on top of the main radiating plane that is connected by the BAR63-02V PIN diode. The main reason to introduce the additional radiating plane is to alter the length of current travelled across the antenna which will in return also reconfigure the resonant frequencies. Figure 1 shows the structure of the reconfigurable antenna. The dimensions of the antenna are listed in Table 1.

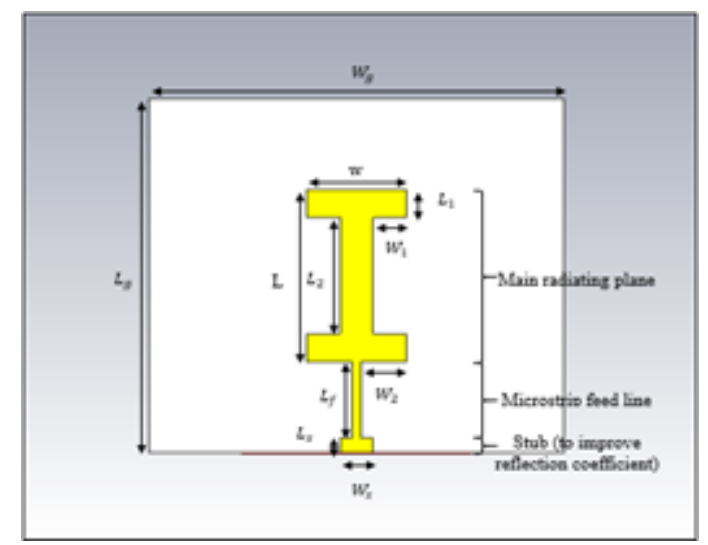

(a)

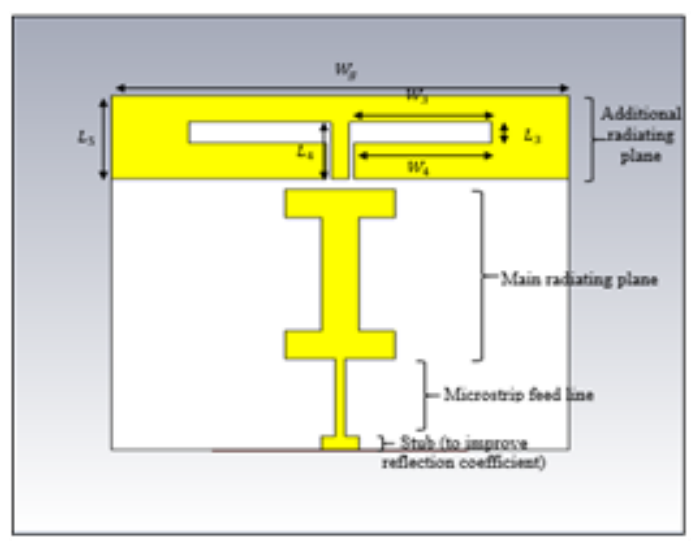

(b)

Figure 1. Reconfigurable antenna with a BAR63-02V PIN diode: (a) With only the main radiation plane (b) With the main and an additional radiating planes 
Table 1. Dimensions of the Reconfigurable Antenna with a BAR63-02V PIN diode

\begin{tabular}{cc}
\hline Parameter & Value $(\mathrm{mm})$ \\
\hline $\boldsymbol{W}_{\boldsymbol{g}}$ & 50 \\
$\boldsymbol{L}_{\boldsymbol{g}}$ & 50 \\
$W$ & 12 \\
$L$ & 23.9 \\
$\boldsymbol{W}_{\mathbf{1}}$ & 4 \\
$\boldsymbol{L}_{\mathbf{1}}$ & 4 \\
$\boldsymbol{W}_{\mathbf{2}}$ & 5.5 \\
$\boldsymbol{L}_{\mathbf{2}}$ & 15.9 \\
\hline
\end{tabular}

\begin{tabular}{cc}
\hline Parameter & Value $(\mathrm{mm})$ \\
\hline $\boldsymbol{W}_{\boldsymbol{s}}$ & 4 \\
$\boldsymbol{L}_{\boldsymbol{s}}$ & 2 \\
$\boldsymbol{L}_{\boldsymbol{f}}$ & 10.8 \\
$\boldsymbol{W}_{\mathbf{3}}$ & 15.5 \\
$\boldsymbol{L}_{\mathbf{3}}$ & 3 \\
$\boldsymbol{W}_{\mathbf{4}}$ & 15 \\
$\boldsymbol{L}_{\mathbf{4}}$ & 8 \\
$\boldsymbol{L}_{\mathbf{5}}$ & 11.9 \\
\hline
\end{tabular}

\subsection{Antenna Simulation}

In the reconfigurable antenna design, a BAR63-02V PIN diode from Infineon Technologies is used as a switch since it has a very low capacitance which provides high isolation. The PIN diode is modeled by using the equivalent circuit model in CST MWS ${ }^{\circledR}$ software. Figure 2(a) shows the discrete port in CST MWS software which can be modelled by the equivalent circuit model of the PIN diode in the ON and OFF states. Figure 2(b) and Figure 2(c) show the equivalent circuit model in the ON and OFF states of the BAR63-02V PIN diode.

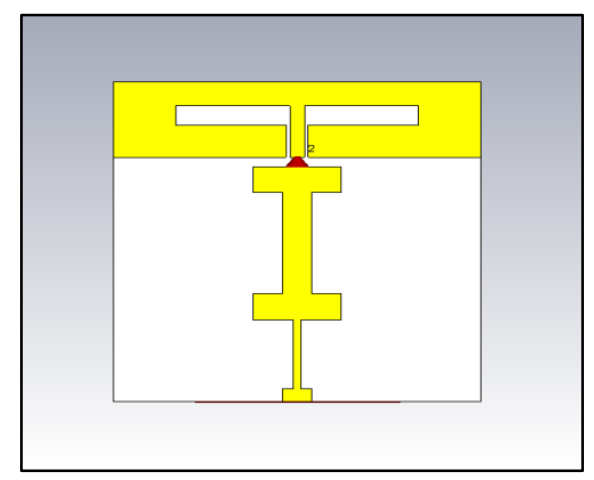

(a)

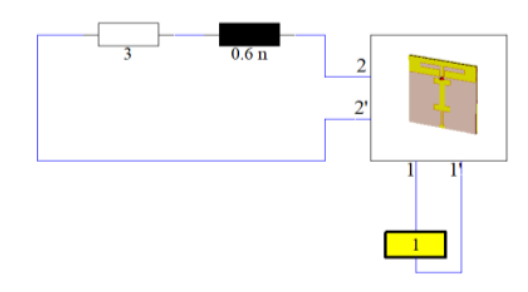

(b)

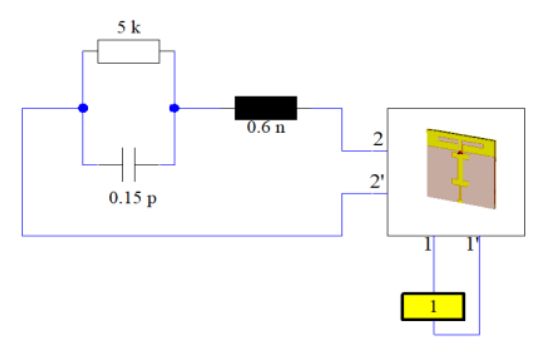

(c)

Figure 2. The reconfigurable antenna with a BAR63-02V PIN diode: (a) The discrete port to connect the main radiation plane to the additional plane (b) Equivalent circuit model of the BAR63-02V PIN diode in the ON state (c) Equivalent circuit model of the BAR63-02V PIN diode in the OFF state

\subsection{Antenna fabrication}

The fabrication process is performed at the Advanced Printed Circuit Board (PCB) Design Laboratory. The outcomes of the fabrication process can be viewed in Figure 3. The antennas are fabricated on a FR-4 substrate with a relative dielectric constant, $\varepsilon_{r}$ of 4.5 , thickness, h of $1.6 \mathrm{~mm}$ and loss tangent, $\tan \delta$ of 0.019. Figure 4 shows the final prototype of the reconfigurable antenna with a BAR63-02V PIN diode and the biasing circuit. 


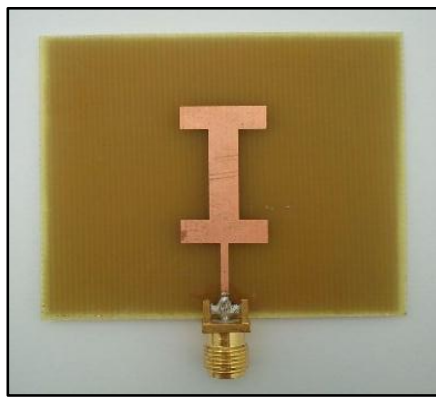

(a)

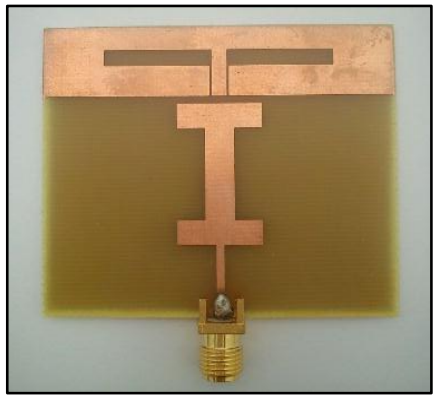

(b)

Figure 3. The fabricated reconfigurable antenna with a BAR63-02V PIN diode: (a) With only the main radiating plane (b) With the main and an additional radiating planes

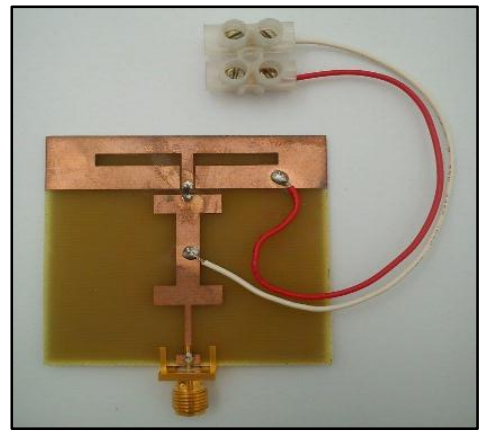

Figure 4. The reconfigurable antenna with a BAR63-02V PIN diode and the biasing circuit

\section{RESULTS AND ANALYSIS}

\subsection{Reconfigurable antenna with the main radiating plane}

The simulation results of reflection coefficient and bandwidth of the antenna and the comparison with the measurement results are shown in Figure 5. From the simulation results, the proposed antenna operates at $5.206 \mathrm{GHz}$ with a reflection coefficient, $\mathrm{S}_{11}$ of $-25.51 \mathrm{~dB}$ and bandwidth, BW of $99.1 \mathrm{MHz}$. The measurement results, on the other hand, show that the $S_{11}$ is the greatest at $5.26 \mathrm{GHz}$ at $-21.48 \mathrm{~dB}$. There is a slight shift in the measurement result with the simulation result of $5.206 \mathrm{GHz}$, which can be attributed to the fabrication losses.

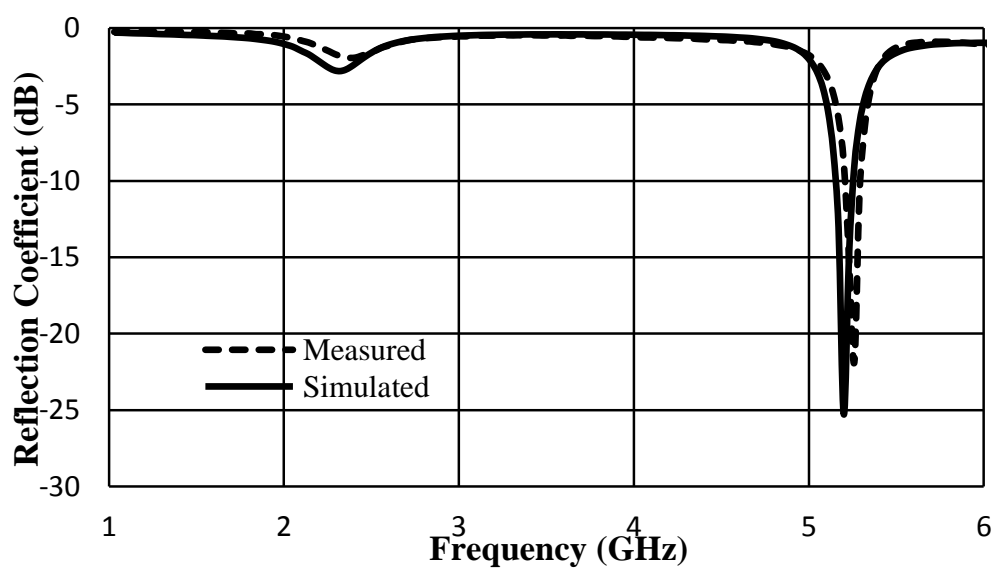

Figure 5. Reflection coefficients of the reconfigurable antenna with only the main radiating plane 
Figure 6 shows the surface current distribution on the main radiating plane. From the figure, the maximum surface current is seen to be concentrated in the middle and around the edges of the radiating plane.

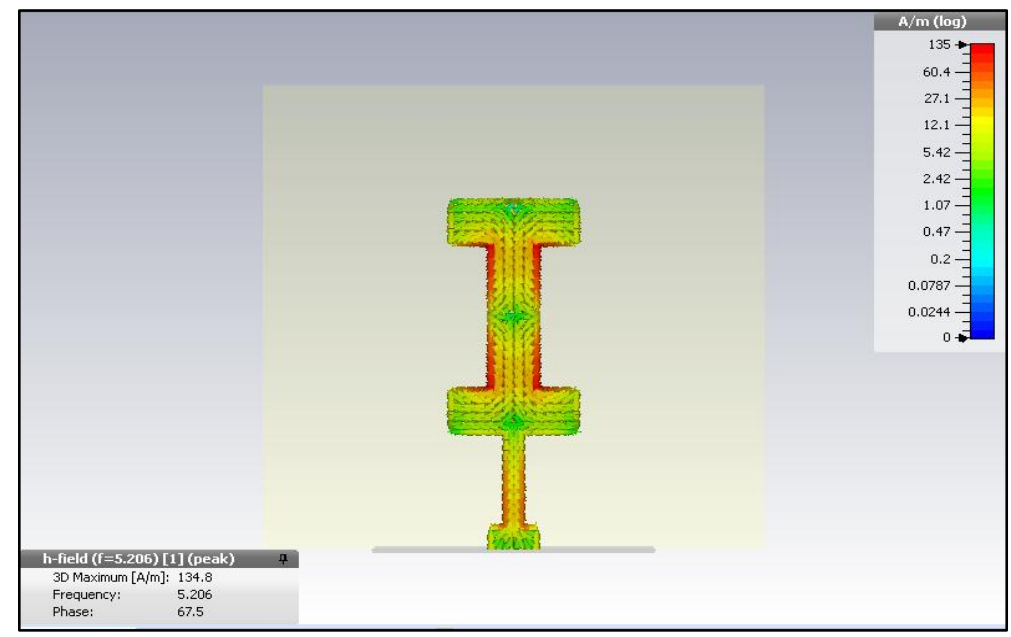

Figure 6. Simulated surface current of the reconfigurable antenna with only the main radiating plane

\subsection{Reconfigurable antenna with the main and additional radiating planes}

The simulation and measurement results of the reflection coefficient and bandwidth of the antenna can be viewed in Figure 7. From the simulation results, it is observed that the antenna is operating at the resonant frequency of $5.302 \mathrm{GHz}$ with the $\mathrm{S}_{11}$ of $-25.385 \mathrm{~dB}$ and $\mathrm{BW}$ of $99.4 \mathrm{MHz}$. The measured $\mathrm{S}_{11}$ of the antenna is the greatest at $5.35 \mathrm{GHz}$ at $-21.52 \mathrm{~dB}$. There is a slight difference between the simulation result of $5.302 \mathrm{GHz}$, which can be attributed to the fabrication losses. In addition, it is also shown that the existence of the additional radiating plane has further increased the resonant frequency to $5.302 \mathrm{GHz}$ from $5.206 \mathrm{GHz}$.

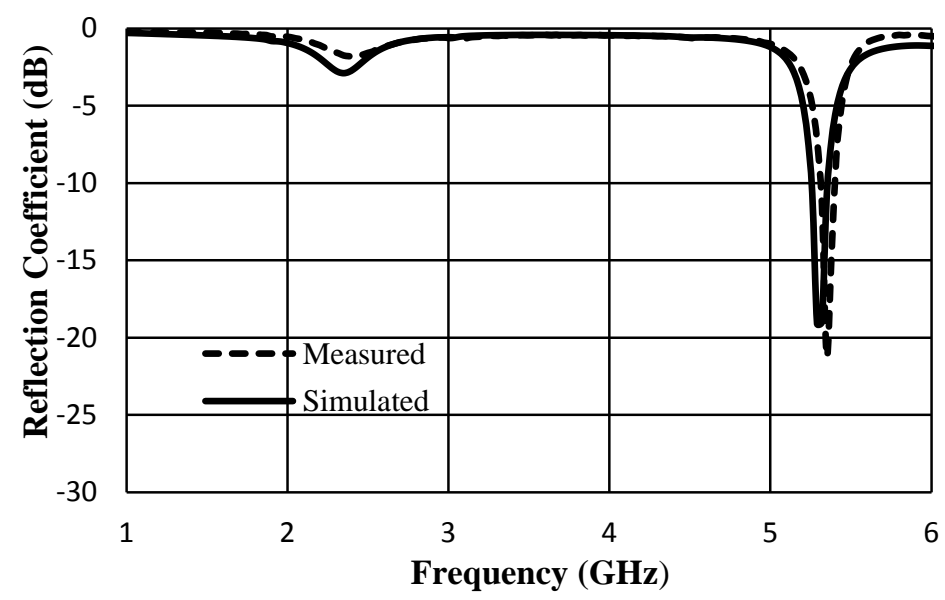

Figure 7. Reflection coefficients of the reconfigurable antenna with two radiating planes

The surface current distribution of the reconfigurable antenna with the main and additional radiating planes can be viewed in Figure 8. Even though there is an additional radiating plane, but there is no current flow between the main and the additional radiating plane since there is no physical connection between the two planes. Therefore, that explains the occurrence of only a single frequency band from the antenna. 


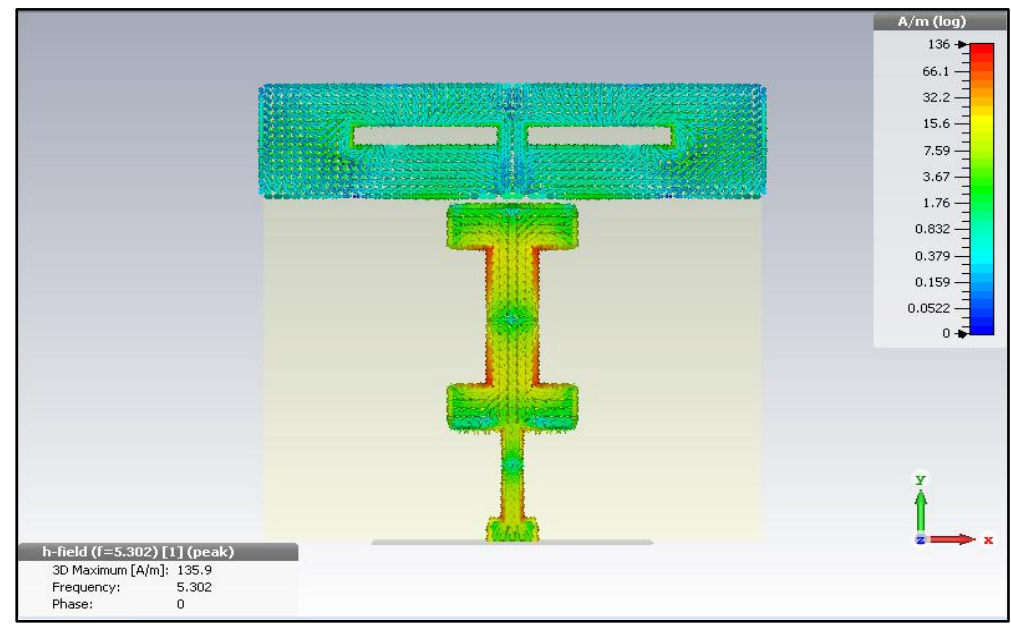

Figure 8. Simulated surface current of the reconfigurable antenna with two radiating planes

\subsection{Reconfigurable antenna with a BAR63-02V PIN diode}

In this work, the PIN diode acts as an active switch and thus, the operations are based on the ON and OFF states of the PIN diode. Figure 9 shows the simulated $\mathrm{S}_{11}$ and BW of the reconfigurable antenna in the $\mathrm{ON}$ and $\mathrm{OFF}$ states. From the figure, the antenna operates at a dual-band frequency of $2.686 \mathrm{GHz}$ and $5.164 \mathrm{GHz}$ in the ON state. For the frequency of $2.686 \mathrm{GHz}$, the $\mathrm{S}_{11}$ and $\mathrm{BW}$ are $-12.1 \mathrm{~dB}$ and $50.6 \mathrm{MHz}$ while for the frequency of $5.164 \mathrm{GHz}$, the $\mathrm{S}_{11}$ and $\mathrm{BW}$ are $-10.822 \mathrm{~dB}$ and $32.2 \mathrm{MHz}$, respectively. In the OFF state, the antenna operates as a single band antenna at a resonant frequency of $5.302 \mathrm{GHz}$ with a $\mathrm{S}_{11}$ and $\mathrm{BW}$ of $-24.835 \mathrm{~dB}$ and $99.8 \mathrm{MHz}$. Therefore, it is shown that in the ON state of the PIN diode, the upper resonant frequency is further reduced to $5.164 \mathrm{GHz}$ as compared to $5.302 \mathrm{GHz}$ when the PIN diode is not present. This can be attributed to the fact that the current travels a longer path from the main radiating plane to the additional plane through the PIN diode that in return, reduces the resonant frequency [10]. It is also shown that the resonant frequency of the reconfigurable antenna in the OFF state of the PIN diode at $5.302 \mathrm{GHz}$ is almost similar (vary slightly) to the resonant frequency of the antenna without the presence of the PIN diode (refer Figure 8).

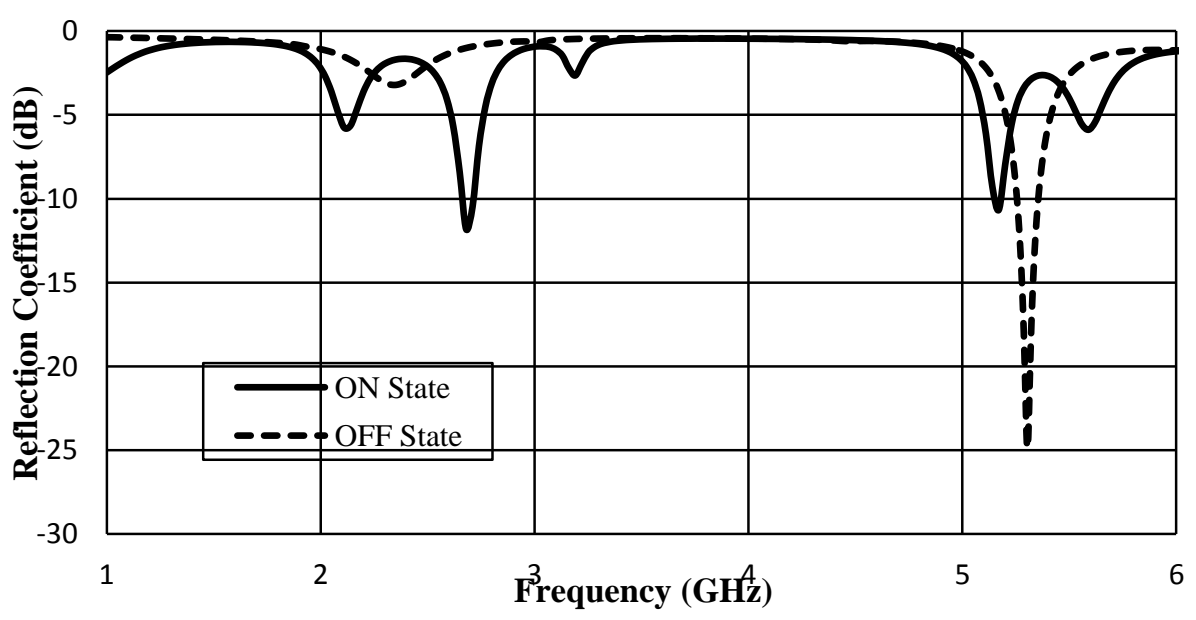

Figure 9. Reflection coefficients of the reconfigurable antenna with a BAR63-02V PIN diode in the ON and OFF states

The reconfigurable antennas are measured by using the ZVB14 Rohde \& Schwarz Vector Network Analyzer (VNA). Due to the lack of facilities, only the reflection coefficients are measured. The 
measurement data retrieved from the VNA also do not reflect the reflection coefficients on display. Therefore, only the screen display of the reflection coefficients are shown in this paper. The reflection coefficients of the reconfigurable antenna in the ON and OFF states can be viewed in Figure 10. In the ON state, a $12 \mathrm{~V} \mathrm{DC}$ voltage is supplied to the antenna to produce a $10 \mathrm{~mA}$ of current across the PIN diode. The power supply is switched off in the OFF state. From Figure $10(\mathrm{a})$, the measured $S_{11}$ are $-11.471 \mathrm{~dB}$ at $2.504 \mathrm{GHz}$ and $-20.131 \mathrm{~dB}$ at $5.210 \mathrm{GHz}$. (The marker at $5.210 \mathrm{GHz}$ is not available on the display). Figure 10(b) shows the measured reflection coefficient of the reconfigurable antenna in the OFF state. From the figure, it can be seen that the antenna operates at $5.26 \mathrm{GHz}$ with a $\mathrm{S}_{11}$ at $-22.36 \mathrm{~dB}$.

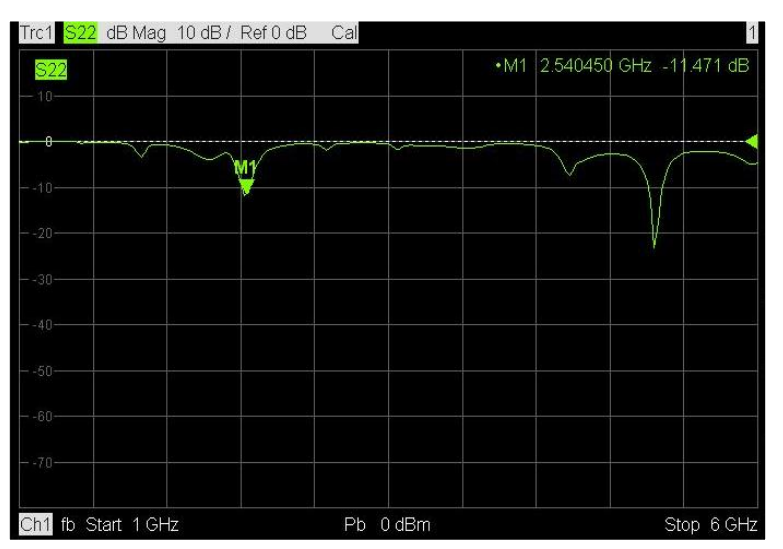

(a)

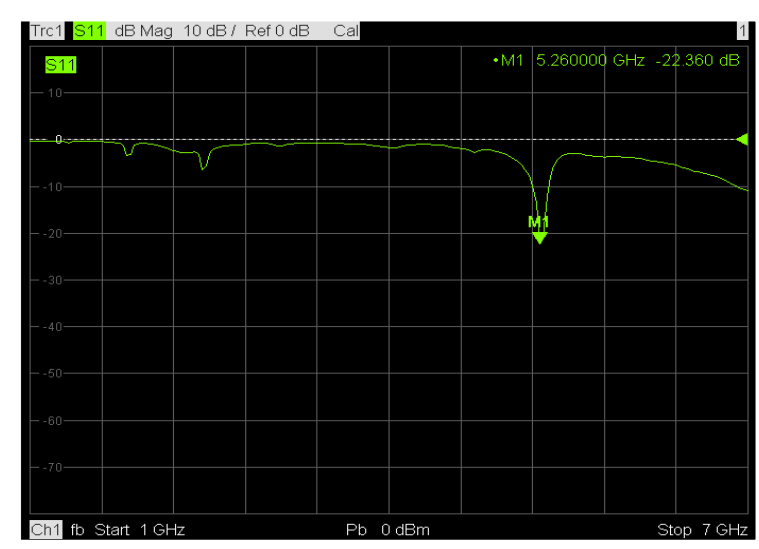

(b)

Figure 10. Measured reflection coefficients of the reconfigurable antenna with a PIN diode in the: (a) ON state (b) OFF state

Figure 11 shows the surface current distribution of the simulated reconfigurable antenna with the PIN diode in the ON state. The current is seen to flow across the main radiating plane to the additional plane that explains the dual-band frequency operation of the antenna at $2.686 \mathrm{GHz}$ and $5.164 \mathrm{GHz}$. It is shown from the figure that the current travels a longer path from the main radiating plane to the additional plane through the PIN diode in both resonant frequencies. From the previous simulation results, it can be concluded that the main radiating plane produces the upper resonant frequency at $5.164 \mathrm{GHz}$ while the additional radiating plane, on the other hand, produces the lower resonant frequency at $2.686 \mathrm{GHz}$. The surface current distribution of the simulated reconfigurable antenna in the OFF state of the PIN diode at $5.302 \mathrm{GHz}$ can be viewed in Figure 12. Since the PIN diode is in the OFF state, there is no current flows through the PIN diode to the additional radiating plane. Thus, the current travels a shorter path which increases the resonant frequency.

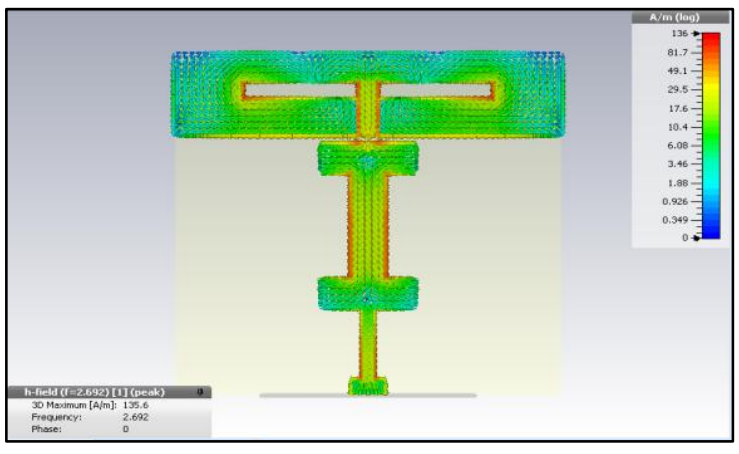

(a)

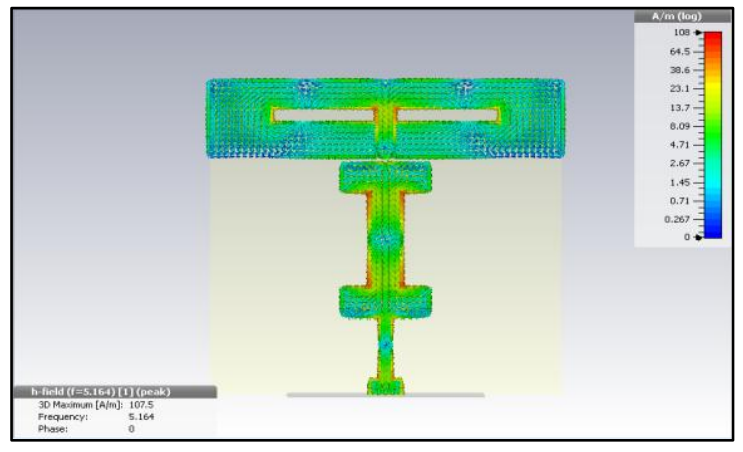

(b)

Figure 11. Simulated surface current of the reconfigurable antenna with a PIN diode in the ON state at:

(a) $2.686 \mathrm{GHz}$ (b) $5.164 \mathrm{GHz}$ 


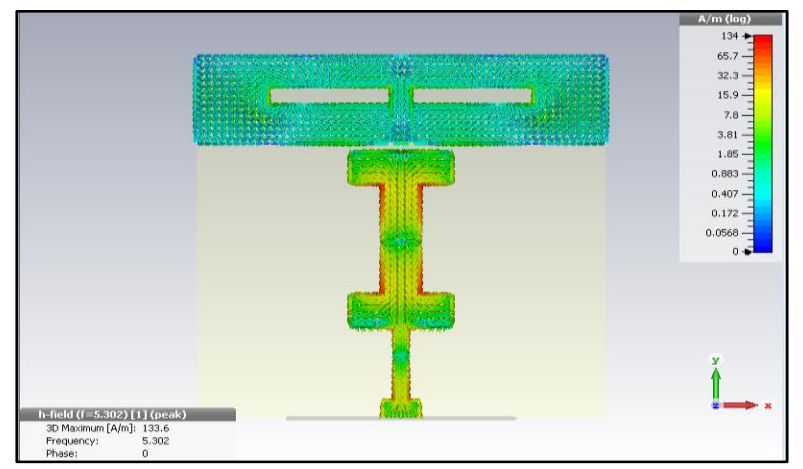

Figure 12. Simulated surface current of the reconfigurable antenna with a PIN diode in the OFF state at $5.302 \mathrm{GHz}$

\section{CONCLUSION}

A reconfigurable antenna with a BAR63-02V PIN diode has been designed, simulated, fabricated and measured in this work. The antenna is fabricated on a FR-4 substrate with a relative dielectric constant, $\varepsilon_{r}$ of 4.5 , thickness, $\mathrm{h}$ of $1.6 \mathrm{~mm}$ and loss tangent, $\tan \delta$ of 0.019 . The equivalent circuit model of the PIN diode has been modelled in the ON and OFF states. In order to switch ON the PIN diode, a 12V DC voltage is supplied to the antenna in order to produce a $10 \mathrm{~mA}$ of current to pass through the PIN diode while in the OFF state, the power supply is switched off. Based on the obtained results, the antenna operates at $2.686 \mathrm{GHz}$ and $5.164 \mathrm{GHz}$ in the ON state which are suitable for LTE2500 and WLAN applications. On the other hand, the antenna operates at $5.302 \mathrm{GHz}$ in the OFF state for WLAN application. The antenna is measured on the ZVB14 Rohde \& Schwarz Vector Network Analyzer.

\section{ACKNOWLEDGEMENTS}

The author would like to acknowledge Universiti Tun Hussein Onn Malaysia for financial assistance.

\section{REFERENCES}

[1] Boutejdar, A., Mohammad, A., Bennani, S. D., \& El Hani, S, (2017), "Design of Compact Monopole Antenna Using double U-DMS resonators for WLAN, LTE, and WiMAX applications", TELKOMNIKA (Telecommunication Computing Electronics and Control), vol. 15, no. 4.

[2] Debogovic, T, (2010), "Perspectives of Reconfigurable Antennas in Modern Wireless Communication and Sensing Systems”, http:/www.fer.hr/_download/repository/Debogovic_kvalifikac ijski.pdf.

[3] Hsieh, H. W., Lee, Y. C., Tiong, K. K., \& Sun, J. S., (2009), "Design of a Multiband Antenna for Mobile Handset Operations", IEEE Antennas and Wireless Propagation Letters, 8, pp. 200-203.

[4] El Maleky, O., Abdelouahab, F. B., Essaaidi, M., \& Abdelfatah, N., (2017), "Miniature design of T-Shaped frequency Reconfigurable antenna for S-Band Application using Switching Technique", International Journal of Electrical and Computer Engineering (IJECE), vol. 7, no. 5, pp. 2426-2433.

[5] Ismail, M. F., Rahim, M. K. A., \& Majid, H. A., (2011, December), "The Investigation of PIN Diode Switch on Reconfigurable Antenna", In RF and Microwave Conference (RFM), 2011 IEEE International, pp. 234-237, IEEE.

[6] Razak, A., Rahim, M. K. A., Majid, H. A., \& Murad, N. A., (2017), "Frequency Reconfigurable Epsilon Negative Metamaterial Antenna", International Journal of Electrical and Computer Engineering (IJECE), vol. 7, no. 3.

[7] Constantine, A. B., (2005), Antenna theory: Analysis and Design, MICROSTRIP ANTENNAS, Third Edition, John Wiley \& Sons.

[8] Kumar, G., \& Ray, K. P., (2003), Broadband Microstrip Antennas, Artech House.

[9] Haupt, R. L., \& Lanagan, M., (2013), "Reconfigurable Antennas", IEEE Antennas and Propagation Magazine, pp. 55, no. 1, pp. 49-61.

[10] Yang, F., \& Rahmat-Samii, Y., (2005), "Patch Antennas with Switchable Slots (PASS) in Wireless Communications: Concepts, Designs, and Applications", IEEE Antennas and Propagation Magazine, vol. 47, no. 2, pp. 13-29. 


\section{BIOGRAPHIES OF AUTHORS}
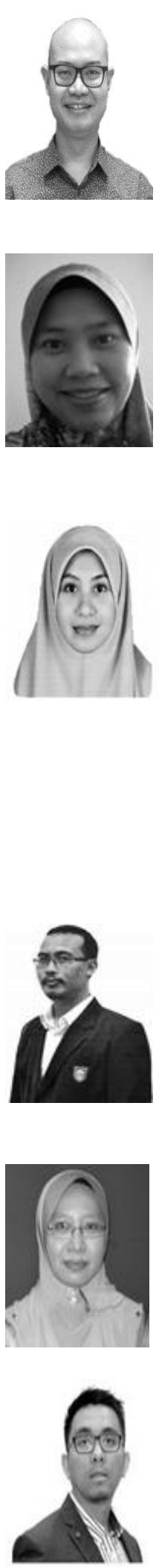

Shaharil Mohd Shah obtained his B. Eng in Microwave and Communication from Multimedia University (MMU) in 2002. He received his M.Sc in Microwave Engineering and Wireless Subsystems Design from the University of Surrey, UK in 2004 and pursuing his Ph.D in Communication Engineering from the University of Birmingham, UK before graduating in 2016. He is currently a senior lecturer in the Department of Communication Engineering, Faculty of Electrical and Electronic Engineering, Universiti Tun Hussein Onn Malaysia (UTHM). His area of research includes, but not limited to, design of microwave devices, active antennas measurement and nonlinear characterisation of active devices.

Zuhairiah Zainal Abidin was born in Kuala Lumpur, Malaysia, in 1978. She received the B.Eng.from the Universiti Teknologi Malaysia, in 2001, the M. Eng from the Kolej Universiti Tun Hussein Onn Malaysia, Johor, Malaysia, in 2003, and Ph.D. degree from Bradford University, U.K in 2011. Currently, she was a Principal Researcher at Applied Electromagnetic Center, Universiti Tun Hussein Onn Malaysia. She has authored and co-authored numbers of journals and proceedings, including the IEEE TRANSACTION ON ANTENNA AND PROPAGATION, MICROWAVE AND OPTICAL TECHNOLOGY LETTERS and IEEE AWPL. Her research interests include MIMO antenna, printed microstrip antenna, wearable antennas, electromagnetic bandgap $(\mathrm{EBG})$ for wireless and mobile and high speed digital circuit's applications.

Fauziahanim Che Seman received the B.Eng. degree in electrical communication from Universiti Teknologi Malaysia. In 2002, she was awarded M.Eng. degree in communication engineering from Kolej Universiti Tun Hussein Onn, now known as Universiti Tun Hussein Onn (UTHM). She received her Ph.D. in electrical engineering Queens University, Belfast, Northern Ireland in 2011. She serves as academician in Department of Communication Engineering, Faculty of Electrical Electronic Engineering at Universiti Tun Hussein Onn Malaysia (UTHM) since 2002. She is also a research fellow in Research Center for Applied Electromagnet (EM-Center). She has authored and co-authored over 40 referred journal and conference technical papers. Due to her significant contributions she has been awarded as Top Scopus Index Author by Publisher's Office, UTHM in 2014. Since 2011, she actively served as an associate reviewer for more than 20 international conferences. Since 2014, she serves on the IEEE Malaysia AP/MTT/EMC Joint Chapter as executive committee. She is actively involves with industrial-academia activities and currently has joint research collaboration with Telekom Malaysia RnD. Her research interests include frequency selective surfaces, antenna design and applied electromagnetics.

Shipun Anuar Hamzah was born in Perak, Malaysia in 1975. He received the B.Eng. and Ph.D. in electrical engineering from Universiti Teknologi Malaysia (UTM), Malaysia in 1998 and 2013, respectively and M.Eng. of Engineering in Communication and Computer System from National University of Malaysia (UKM), Selangor, Malaysia, in 2000. From 1998 to 2004, he worked as a lecturer at Kolej UNITI Sdn. Bhd, Malaysia. Since April 2004, he has been working as a Lecturer at the Faculty of Electrical and Electronic Engineering, Universiti Tun Hussein Onn Malaysia (UTHM). He is now a Senior Lecturer with the same institution. His research interests include active antenna, harmonic suppression antenna, rectifying-antenna and RF propagation.

Norshidah Katiran received her Ph.D in Electrical Engineering from Universiti Teknologi Malaysia, in 2015, her M.Eng. degree in Communication and Computer Engineering from Universiti Kebangsaan Malaysia, in 2004, and her B.Eng. degree in Electrical Engineering (Telecommunications) from Universiti Teknologi Malaysia, in 2001. Currently, she is a Senior Lecturer in the Department of Communication Engineering at Universiti Tun Hussein Onn Malaysia. Her major research interests include optimization of resource allocation in cooperative networks and multiple input multiple output (MIMO) transmissions.

Farid Zubir received the B. Eng. degree in Electrical Engineering majoring in Telecommunication as well as M. Eng. degree (Communication) from the Universiti Teknologi Malaysia in 2008 and 2010 respectively. In 2016, he then obtained his Ph.D degree from the University of Birmingham, UK, for research into direct integration of power amplifiers with antennas in microwave transmitters. He is currently serves as a Senior Lecturer at the Department of Communication Engineering, Faculty of Electrical Engineering, Universiti Teknologi Malaysia. His current research interest and specialization are in the area of RF and Microwave technologies including Planar Array Antennas, Dielectric Resonator Antennas (DRAs), Active Integrated Antenna (AIA), Microstrip Reflectarray Antenna (MRA), Millimeter wave Antennas, Electromagnetic Band Gap (EBG), Artificial Magnetic Conductor (AMC), Full-integrated Transmitting Amplifiers, Linear PAs, Doherty PAs and Bias Decoupling Circuits. He has published over 40 articles in journals, book chapters, conference papers and proceedings. 